\title{
A New Control Method to Reduce the Low-Frequency Output Current Ripple of AC-DC Converters by Using Virtual Inductor
}

\author{
Pekik A. Dahono \\ School of Electrical Engineering and Informatics, \\ Institut Teknologi Bandung, Bandung, Indonesia \\ Email:padahono@yahoo.com
}

\begin{abstract}
A new concept of virtual inductor to reduce the low-frequency dc output current ripple of ac-dc converters is introduced in this paper. Virtual inductor is defined as an additional control algorithm that changes the system behavior into the one that has an additional inductor connected on it. The virtual nature of the inductor makes the inductance can be designed without weight and volume restrictions. How to use the virtual inductor to improve the performance of converter current controller is discussed in this paper. Several simulated and experimental results are included to show the validity of the proposed concept.
\end{abstract}

Keywords: current controller; power converter; virtual inductor.

\section{Introduction}

A controllable dc current source is used in various applications such as electrochemical industries, dc arc furnaces, cathodic protection, and magnetic laboratories [1-4]. A very low-ripple dc current source is desirable in these applications. For large current applications, the dc current is usually obtained by using a phase-controlled thyristor rectifier. For medium and small current applications, a combination of diode rectifier and dc-de converter is commonly used. In recent years, the latest topology has also been proposed for large power applications. When the ac input voltage is unbalanced, phase-controlled thyristor produces a low-frequency current ripple that is difficult to filter out. Similarly in dc-de converter, nonideal dc input voltage produces a large lowfrequency output current ripple. Various methods to minimize this lowfrequency output current ripple were proposed in the literature [5-18]. Most of the methods were based on feedforward technique. Feedforward technique needs additional input voltage sensor and needs an accurate adjustment of feedforward gain. A nonlinear feedforward technique has also been proposed but the design is complicated. Moreover, nonlinear controller is usually results in variable switching frequency which is undesired in many applications.

Received September $21^{\text {st }}, 2010$, Revised June $14^{\text {th }}, 2011$, Accepted for publication October $25^{\text {th }}, 2011$. Copyright (C) 2012 Published by LPPM ITB \& PII, ISSN: 1978-3051, DOI: 10.5614/itbj.eng.sci.2012.44.1.4 
In this paper, a new approach to reduce the low-frequency output current ripple of ac-dc power converters is proposed. The proposed method is based on new concept of virtual inductor. A virtual inductor is defined as an additional controller that changes the behavior of the system into the one that has a large inductor connected on it. The virtual inductor can be designed to have a characteristic that cannot be possessed by a real inductor. A virtual inductor can be designed to respond only the error component of the output current or just respond to the disturbance signal. Several simulated and experimental results are included in this paper to show the validity of the proposed concept.

\section{Four-Quadrant DC Current Sources}

For large power applications, a four-quadrant current source is usually implemented by using a four-quadrant thyristor converter as shown in Figure 1. For small and medium power applications, a four-quadrant dc-dc converter as shown in Figure 2 is commonly used. The dc voltage source for the dc-dc converter is usually obtained from an ac voltage source by using a diode rectifier. In these figures, the load is represented as a series connection of a resistance, an inductance, and an emf.

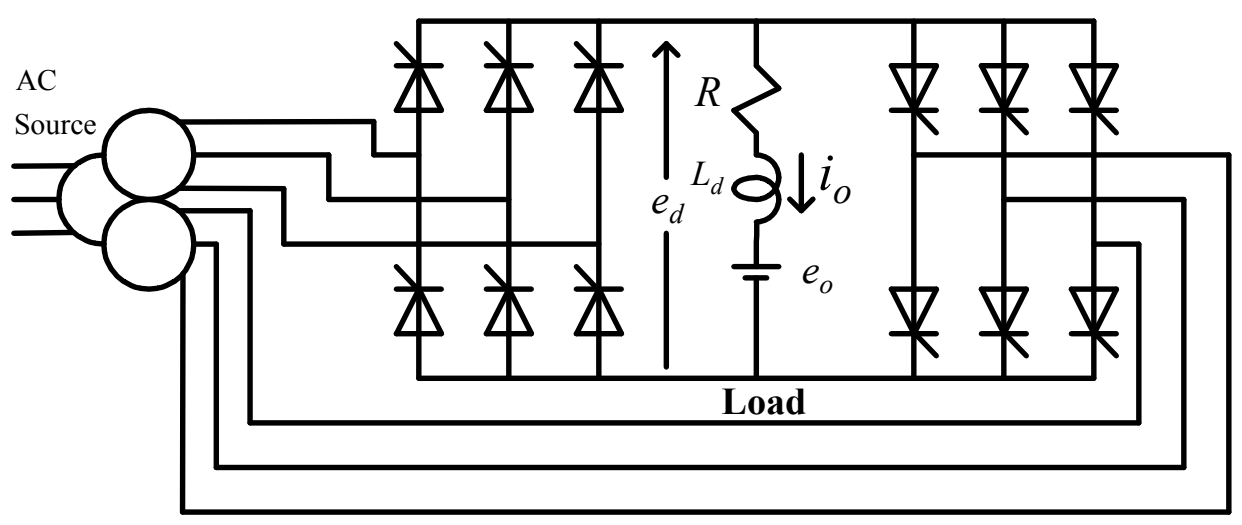

Figure 1 Four-quadrant thyristor converter.

When the ac source is unbalanced, a polyphase thyristor rectifier produces a low-frequency output current ripple. Because the frequency is low, the required output filter inductor is very large if the output current ripple must be minimized by using only the filter inductor. This low-frequency output current ripple still exist even if the phase number of rectifier is increased.

In the case of a combination of a diode rectifier and a dc-dc converter, the lowfrequency voltage ripple in the dc link (dc voltage capacitor between the rectifier and dc-dc converter) results in dc-dc converter low-frequency output 
current ripple. The low-frequency voltage ripple in the dc link is produced because of ac source voltage unbalances and small dc filter capacitances. The low-frequency output current ripple is especially noticeable when the ac voltage source is single-phase.

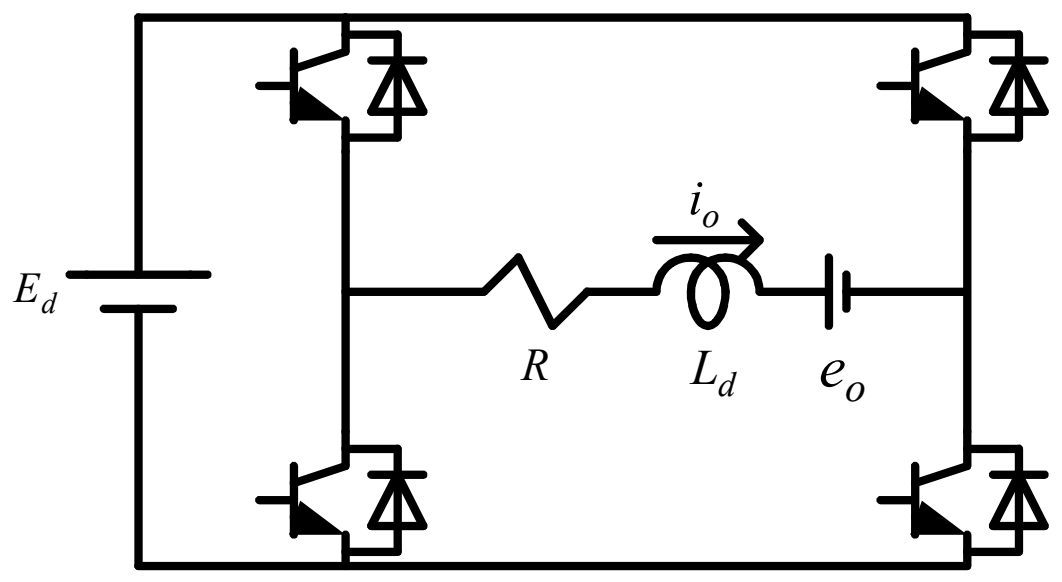

Figure 2 Four-quadrant dc-dc converter.

Figure 3 shows simulated results of three-phase four-quadrant thyristor rectifier under balanced and unbalanced conditions. In this simulation, it is assumed that the output current is controlled by using a proportional-integral (PI) current controller. Unbalanced condition is created by using a small inductor that is inserted in series to the one phase of the ac source. It can be seen that a lowfrequency $(100 \mathrm{~Hz})$ output current ripple is generated when the ac voltage source is unbalanced. Of course, the low-frequency output current ripple can be minimized by increasing the size of the filter inductor but the required inductor will be very large. The low-frequency output current ripple can also be minimized by increasing the gain of the PI current controller but the maximum gain is limited by the stability of the system. Increasing the pulse number will not improve the situation.

Figure 4 shows simulated results of combination of a single-phase diode rectifier and a dc-dc converter. It is assumed that a PI current controller is used to control the output current. A switching frequency of $5 \mathrm{kHz}$ was used to control the dc-dc converter. Because the dc voltage across the filter capacitor is not ripple free, a low-frequency $(100 \mathrm{~Hz})$ output current ripple is generated on the output of dc-dc converter. The low-frequency output current ripple is especially noticeable when the dc filter capacitance is small. The low-frequency output current ripple cannot be eliminated by increasing the switching frequency of dc-dc converter. 


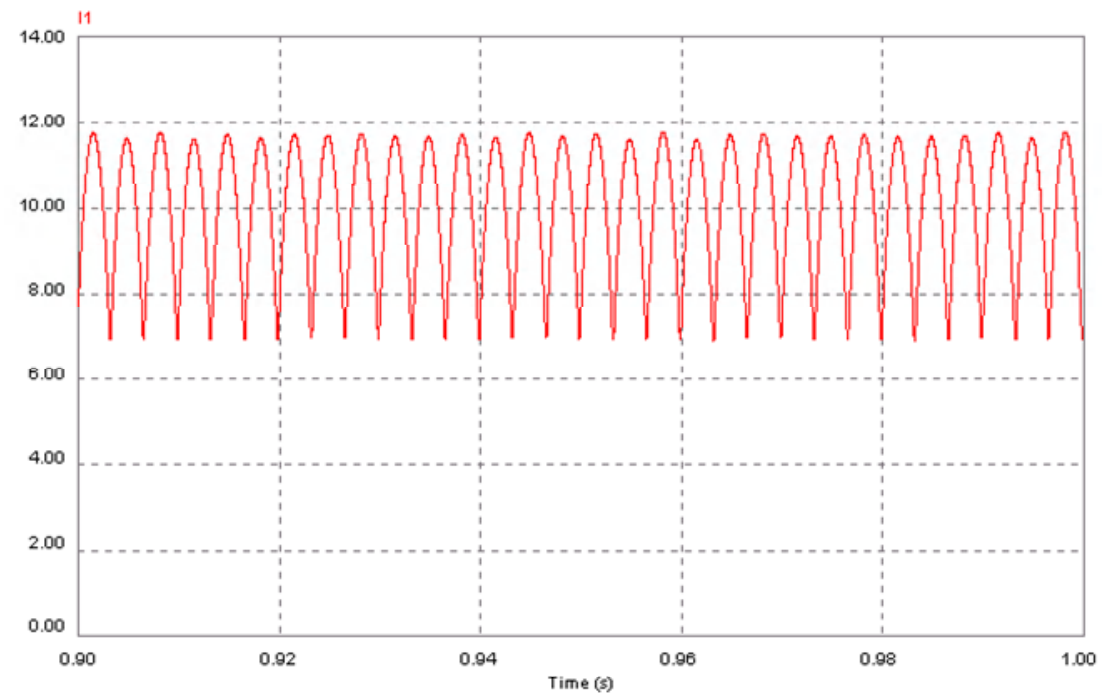

(a) Balanced condition.

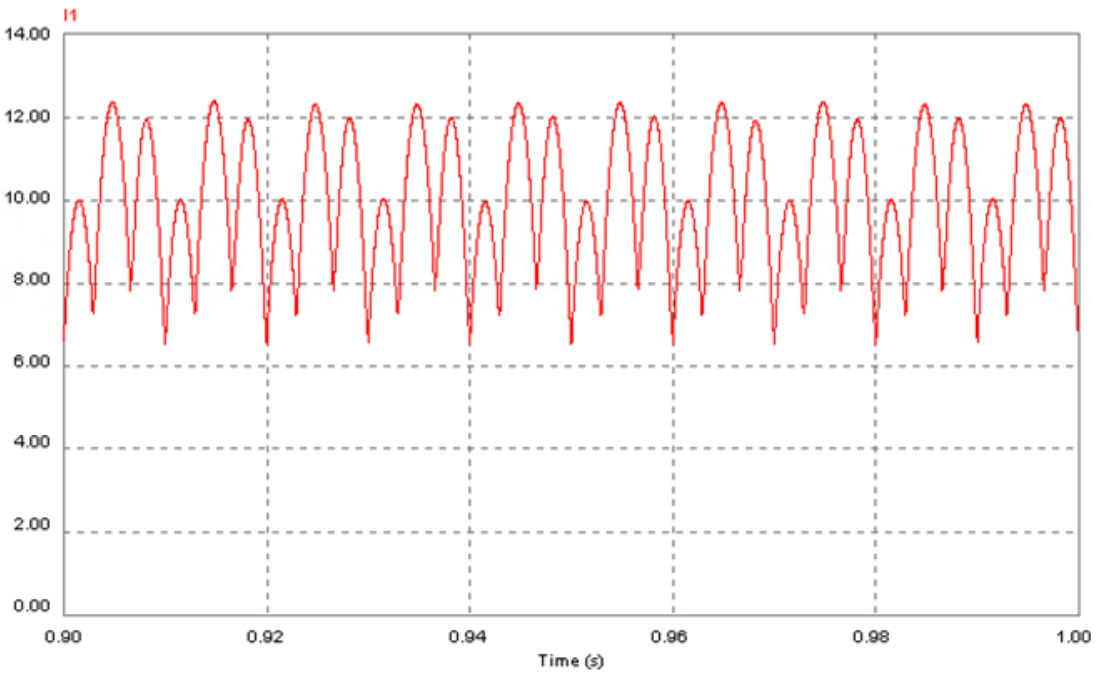

(b) Unbalanced condition.

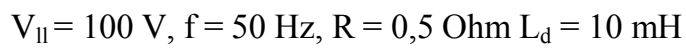

(Ver : $2 \mathrm{Amp} / \mathrm{div}$ Hor : 0,02 s/div)

Figure 3 Simulated results of thyristor converter under balanced and unbalanced conditions. 
Reduce the Low-Frequency Output by Using Virtual Inductor 53

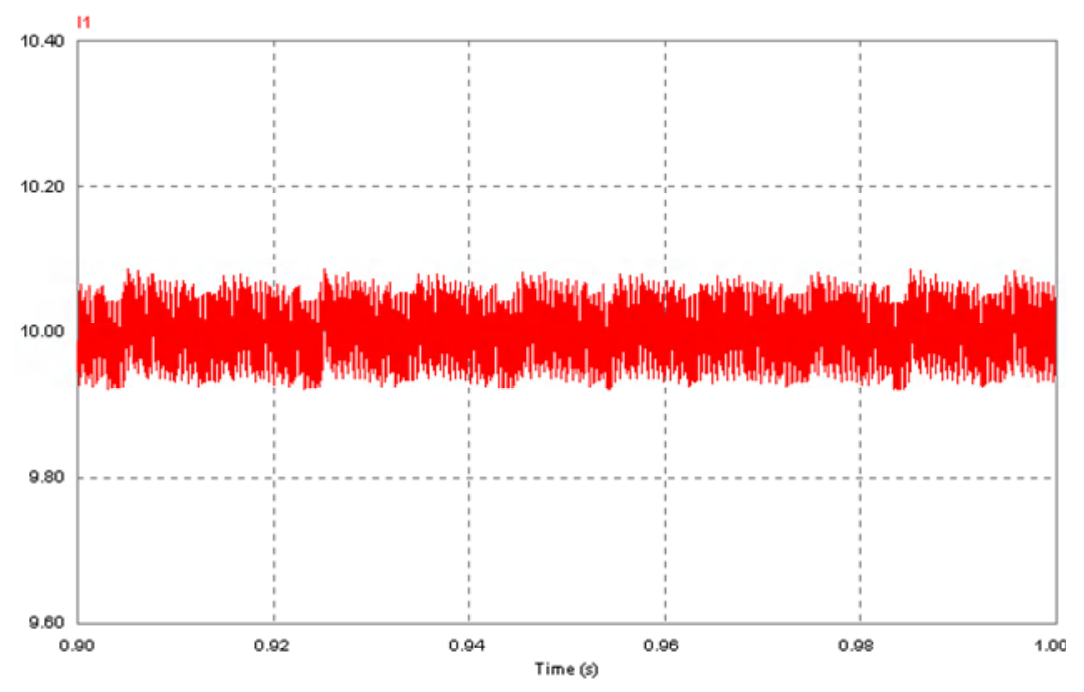

(a) DC filter capacitor $500 \mu F$.

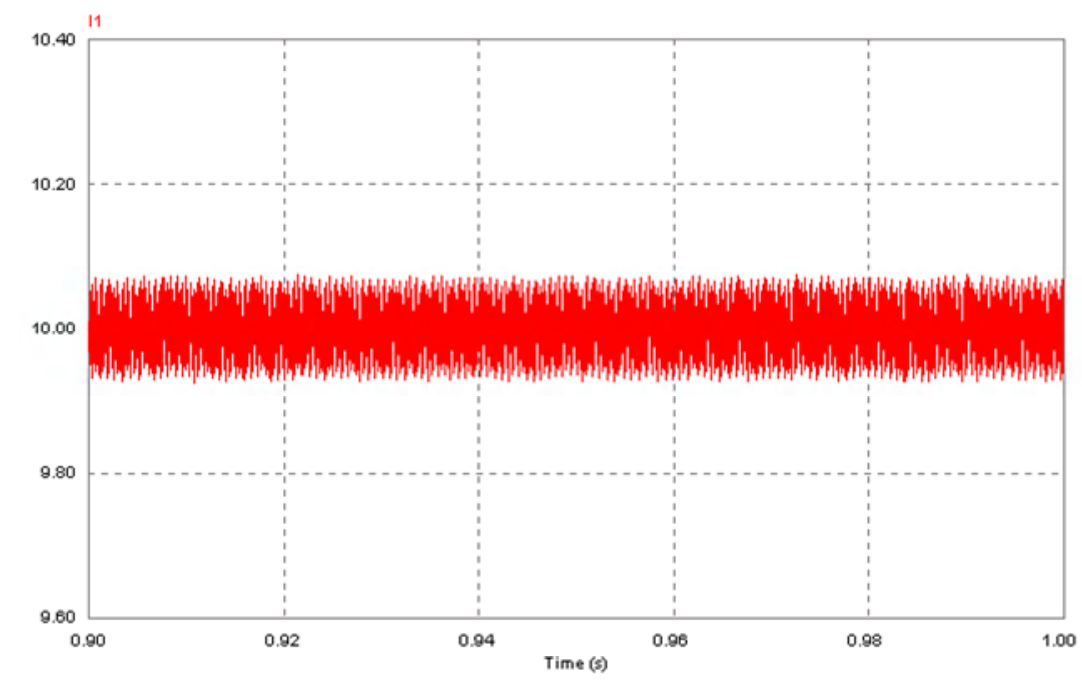

(b) DC filter capacitor $2000 \mu F$.

$R=0,5 \mathrm{Ohm} L_{d}=10 \mathrm{mH}$ Switching frequency $2000 \mathrm{~Hz}$

(Ver : 0,2 Amp/div Hor : 0,02 s/div)

Figure 4 Simulated results of dc-dc converter under small and large dc filter capacitors. 


\section{Virtual Inductor}

In order to explain the proposed virtual inductor, the dc-dc converter as shown in Figure 2 will be used. The same approach can be used for phase-controlled thyristor converters.

Figure 5(a) shows the block diagram of dc-dc converter. In this figure, $\bar{E}_{d}$ is the nominal value of dc-voltage source. It is assumed that an additional inductor $L_{v}$ is connected in series to the load. Based on that figure, the following output current response can be obtained:

$$
I_{o}(s)=\frac{K_{p} \bar{E}_{d}\left(1+s T_{I}\right) I_{r e f}(s)}{K_{p} \bar{E}_{d}\left(1+s T_{I}\right)+s^{2}\left(L_{d}+L_{V}\right) T_{I}}-\frac{s T_{I} N(s)}{K_{p} \bar{E}_{d}\left(1+s T_{I}\right)+s^{2}\left(L_{d}+L_{V}\right) T_{I}}
$$

where

$$
N(s)=\tilde{E}_{d}(s)-E_{o}(s)-R I_{o}(s)
$$

and $\widetilde{E}_{d}(s)$ represents the effect of dc source voltage ripple on the output of dcdc converter. $K_{p}$ and $T_{I}$ are proportional and time constants of PI current controller. Eq. (1) shows that the effect of disturbance signal $N(s)$ can be minimized by adjusting the gain of PI current controller. This adjustment, however, cannot be done without changing the response of output current to the reference signal. Moreover, the gain of current controller is limited by the stability of system and sensitivity to noise.

Eq. (1) also shows that the effect of disturbance signal can be minimized by increasing the value of the additional inductance $L_{v}$. However, the required additional inductance will be large and expensive if the frequency of the ripple is low. In order to solve this problem, a virtual inductor can be used. The virtual inductor can be obtained through block diagram modification. A block diagram as shown in Figure 5(b) can be obtained through block diagram manipulation of block diagram in Figure 5(a). In Figure 5(b), the effect of additional inductor is obtained by using a differentiator as shown in the figure. Because both block diagrams are equivalent, the output current response of Figure 5(b) is the same as the one of Figure 5(a). Though the virtual inductor in Figure 5(b) has solved the problem of inductor size, the output current response is still influenced by the additional inductor. We need a virtual inductor that suppressing the effect of disturbance signal but no effect to the reference signal.

If the virtual inductor that affecting only the disturbance signal is desired, $L_{v} \alpha(s) / L_{d}$ must not be injected into the summing point. Thus, the block diagram of Figure 5(b) must be modified into the one as shown in Figure 5(c). 
Reduce the Low-Frequency Output by Using Virtual Inductor 55

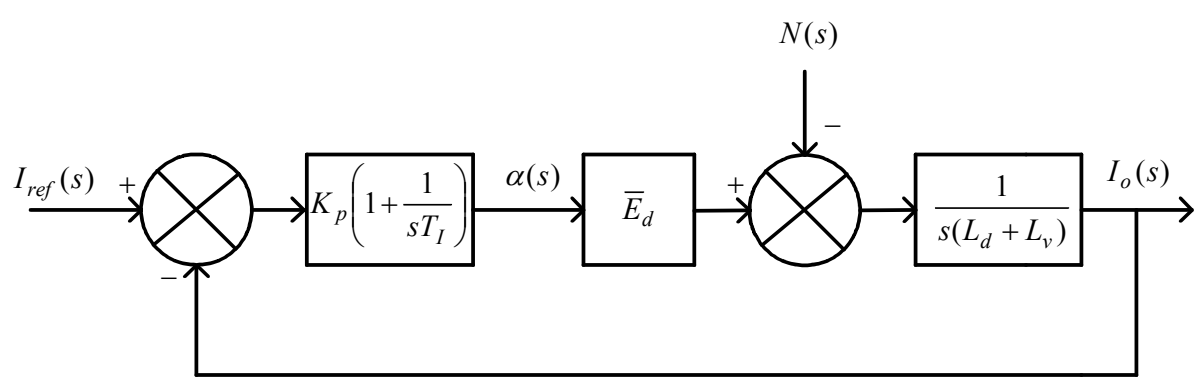

(a)

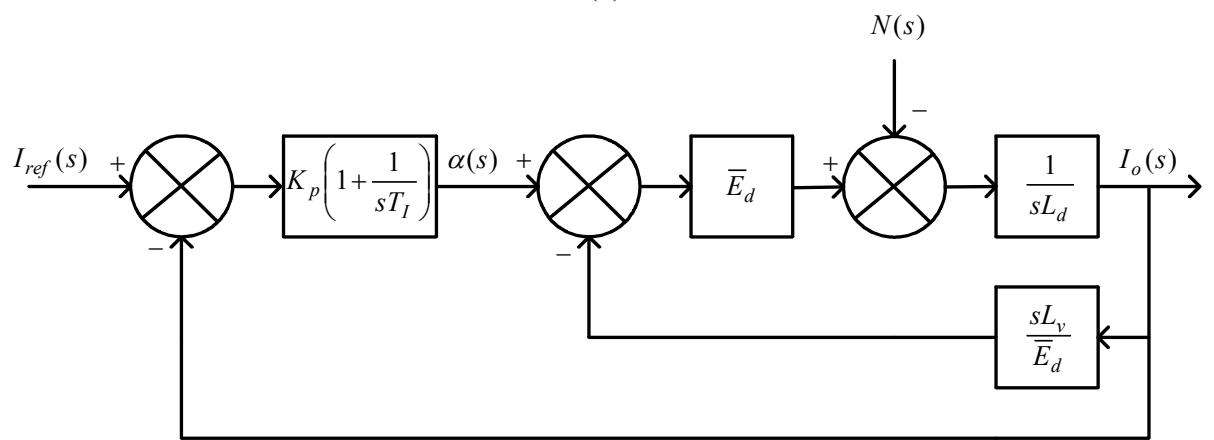

(b)

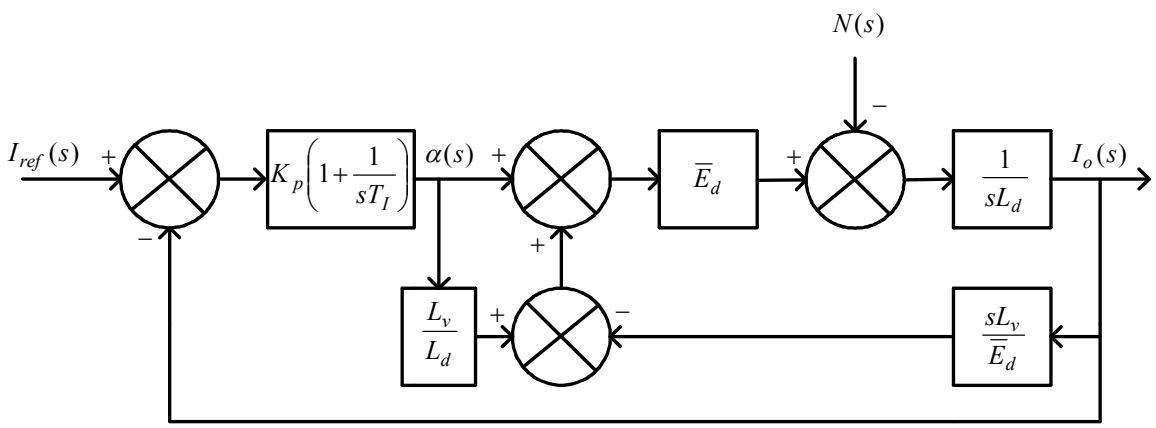

(c)

Figure 5 Developments of virtual inductor.

With this block diagram, the output current response is

$$
I_{o}(s)=\frac{K_{p} \bar{E}_{d}\left(1+s T_{I}\right) I_{r e f}(s)}{K_{p} E_{d}\left(1+s T_{I}\right)+s^{2} L_{d} T_{I}}-\frac{s T_{I} N(s)}{\left(1+\frac{L_{v}}{L_{d}}\right)\left(s^{2} L_{d} T_{I}+s T_{I} K_{p} \bar{E}_{d}+K_{p} \bar{E}_{d}\right)}
$$


Eq. (3) shows that the virtual inductance $L_{v}$ can be increased without affecting the output current response to the reference current. It can be shown that if the virtual inductance $L_{v}$ is chosen to be equal to the load inductance $L_{d}$ the proposed virtual inductance concept has the same form as feedforward concept based on disturbance observer [16-18]. In practice, a low-pass filter must be inserted on the output of virtual inductance to suppress the noise effects. It should be noted that the virtual inductor concept has a similar form to the controller that is derived by using a disturbance observer concept. Thus, disturbance observer in this application is just a special case of virtual inductor concept.

\section{Experimental Results}

In order to verify the proposed virtual inductor concept, a small experimental system was constructed. Bipolar power transistor modules were used as the main switching devices of the dc-dc converter. The dc voltage source was obtained from an ac voltage source of $50 \mathrm{~Hz}$ by using a single-phase diode rectifier. The ac voltage source is adjusted in such a way so that the dc voltage source is maintained almost constant at $100 \mathrm{Vdc}$. A dc filter capacitor of $500 \mu \mathrm{F}$ was used to smoothing the de voltage. Because a small capacitor was used a low-frequency voltage ripple of $100 \mathrm{~Hz}$ is noticeable in the dc voltage source. The bipolar power transistors were switched at $2000 \mathrm{~Hz}$. A proportional gain of 1.8 and time constant of $0.004 \mathrm{~s}$ were used for the PI current controller. First order Chebyshev low-pass filter with cut-off frequency of $1000 \mathrm{~Hz}$ was used to minimize the noise. The virtual inductor is implemented by using discrete analog components. A series connection of a resistance $5 \Omega$ and an inductance of $10 \mathrm{mH}$ was used as the load.

Figure 6(a) shows the output current when no virtual inductor was used. As a small dc capacitor was used in this experiment, the dc input voltage of dc-dc converter is rich of ripple. The most dominant dc input voltage ripple is the 100$\mathrm{Hz}$ ripple. Because of the dc input voltage ripple, it can be seen clearly that the load current has a low-frequency ripple component. The amplitude of the ripple is about $300 \mathrm{~mA}$. The frequency of the current ripple is $100 \mathrm{~Hz}$ the same as the frequency of the dc input voltage ripple.

Figures 6(b) and 6(c) show the converter output currents when the virtual inductor is used. The low-frequency output current ripple is reduced when the virtual inductor is increased. For virtual inductance equal to five times of the load inductance, the load current ripple is reduced up to $50 \mathrm{~mA}$. The remaining 
Reduce the Low-Frequency Output by Using Virtual Inductor 57

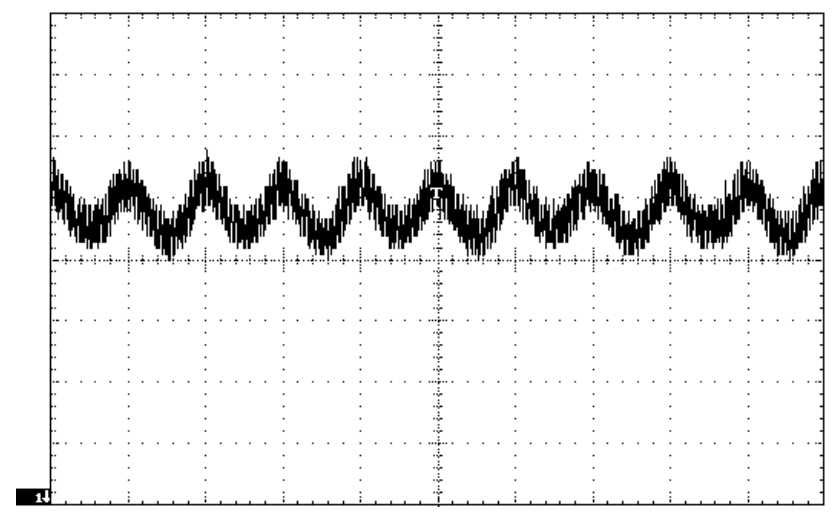

(a) Without virtual inductor.

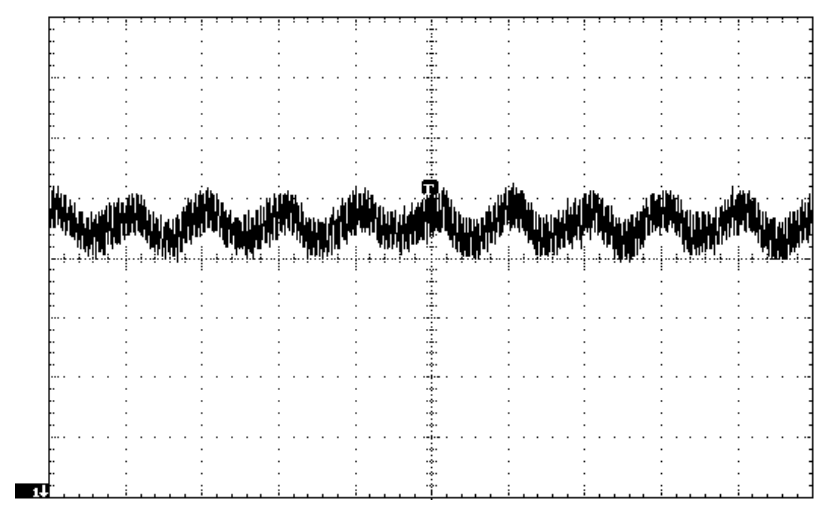

(b) Virtual inductor $L_{v}=L_{d}$.

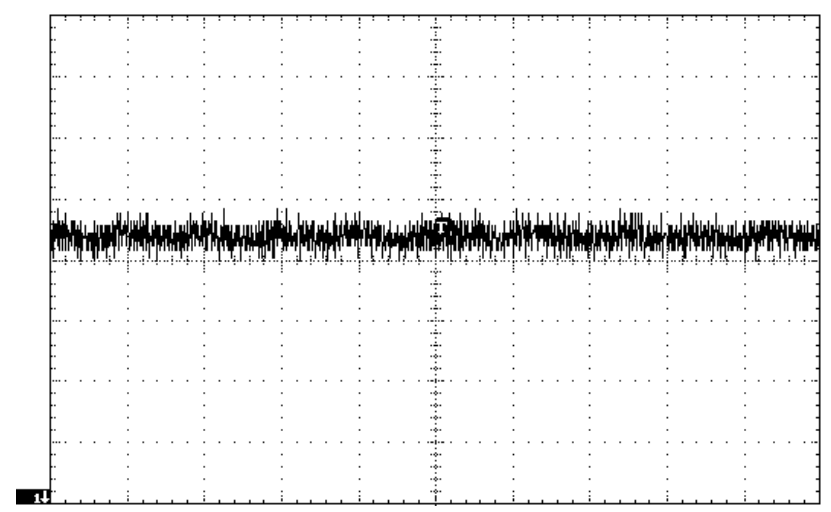

(c) Virtual inductor $L_{v}=5 L_{d}$.

Ver : $200 \mathrm{~mA} /$ div Hor : $10 \mathrm{~ms} /$ div.

Figure 6 Experimental results under steady-state conditions. 


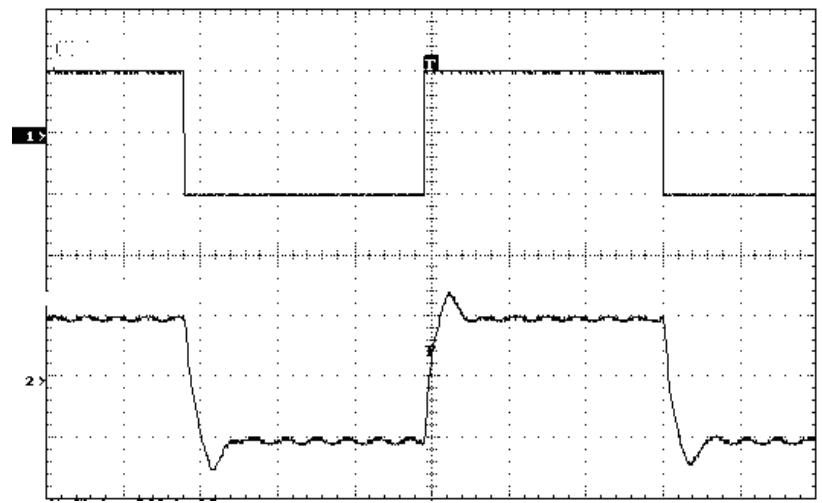

(a) Without virtual inductor.

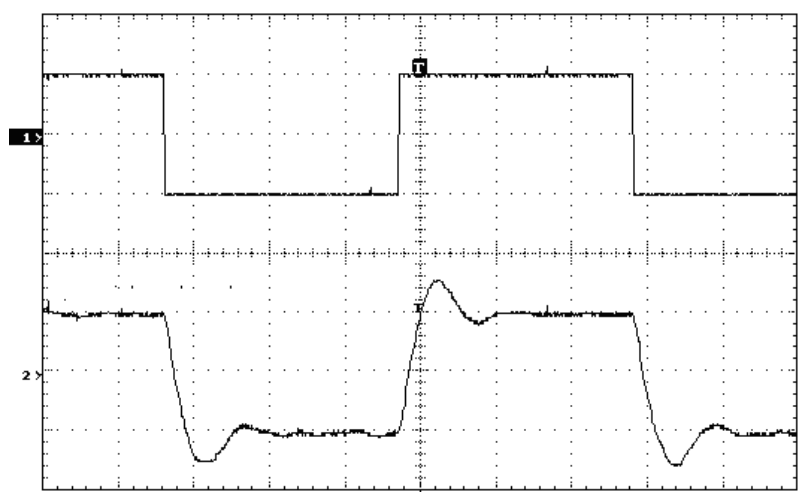

(b) With virtual inductor $L_{v}=5 L_{d}$.

Ver : $5 \mathrm{~A} / \mathrm{div}$ Hor : $25 \mathrm{~ms} /$ div. Upper : Reference current Lower : Load current

Figure 7 Transient response of load current.

ripple is just the high-frequency switching ripple. The virtual inductance cannot be too large because the system will be sensitive to noise. A wise compromise must be taken between noise sensitivity and ripple suppression.

Figures 7(a) and 7(b) show the output current transient responses without and with virtual inductor. The output current reference is changing periodically from positive value to negative value and vice versa. In this experiment, the inductance of virtual inductor is five times the load inductance. It can be seen clearly that the virtual inductor has almost no effect on the transient response of load current. Thus, the low-frequency ripple can be suppressed without affecting the transient response. The converter current controller can be designed separately from the design of virtual inductor. 


\section{Conclusion}

A new virtual inductor concept has been introduced in this paper. The proposed virtual inductor concept can be used to improve the performance of output current controller of static power converters. Simulated and experimental results have shown the effectiveness of the proposed method. By using the proposed virtual inductor concept, the low-frequency output current ripple of dc-dc converter can be reduced significantly without affecting the transient response. Applications of the proposed method to other applications are left for future investigation.

\section{Acknowledgment}

The author wish to thank Diah Wulandari, former student at the School of Electrical Engineering and Informatics, Institute of Technology Bandung, for her assistance during the experiments.

\section{References}

[1] Siebert, A., Troedson, A. \& Ebner, S., AC to DC Power Conversion Now and in the Future, IEEE Trans. Ind. Appl., 38, pp. 934-940, July/August 2002.

[2] Rodriguez, J. R., Pontt, J., Silva, C., Wiechmann, E.P., Hammond, P.W., Santucci, F.W., Alvarez, R., Musalem, R., Kouro, S. \& Lezana, P., Large Current Rectifiers: State of the Art and Future Trends, IEEE Trans. Ind. Electr., 52, pp. 738-746, June 2005.

[3] Ladoux, P., Postiglione, G., Foch, H. \& Nuns, J., A Comparative Study of $A C / D C$ Converters for High-Power DC Arc Furnaces, IEEE Trans. Ind. Electr., 52, pp. 747-757, June 2005.

[4] Wiechmann, E.P., Aqueveque, P., Morales, A.S., Acuna, P.F. \& Burgos, R., Multicell High-Current Rectifiers, IEEE Trans. Ind. Appl., 44, pp. 238-246, Jan/Feb. 2008.

[5] Maswood, A., Joos, G., Ziogas, P.D. \& Lindsey, J.F., Problems and Solutions Associated with the Operation of Phase-Controlled Rectifiers under Unbalanced Input Voltage Conditions, IEEE Trans. Ind. Appl., 27, pp. 765-772, July/August 1991.

[6] Ngandui, E., Olivier, G., April, G.E. \& Guimaraes, C., DC Harmonic Distortion Minimization of Thyristor Converters under Unbalanced Voltage Supply Using Asymmetrical Firing Angle, IEEE Trans. Power Electr., 12, pp. 332-342, March 1997.

[7] Calderone, L., Pinola, L. \& Varoli, V., Optimal Feedforward Compensation for PWM DC/DC Converters with Linear and Quadratic Conversion Ratio, IEEE Trans. Power Electr., 7, pp. 349-355, April 1992. 
[8] Jin, H., Joos, G., Pande, M. \& Ziogas, P., Feedforward Techniques Using Voltage Integral Duty-Cycle Control, Proc. IEEE Power Electr. Spec. Conf., pp. 370-377, 1992.

[9] Jin, H., Dewan, S.B. \& Lavers, J.D., A New Feedforward Control Technique for AC-DC Switchmode Power Supplies, Proc. IEEE Applied Power Electr. Conf., pp. 376-382, 1992.

[10] Tang, W., Lee, F.C., Ridley, R.B. \& Cohen, I., Charge Control: Modeling, Analysis, and Design, IEEE Trans. Power Electr., 8, pp. 396403, Oct. 1993.

[11] Garofalo, F., Marino, P., Scala, S. \& Vasca, F., Control of $D C-D C$ Converters with Linear Optimal Feedback and Nonlinear Feedforward, IEEE Trans. Power Electr., 9, pp. 607-615, Nov. 1994.

[12] Liu, Y.F. \& Sen, P.C., A Novel Method to Achieve Zero-Voltage Regulation in Buck Converter, IEEE Trans. Power Electr., 10(3), pp. 292301, May 1995.

[13] Smedley, K.M. \& Cuk, S., One Cycle Control of Switching Converters, IEEE Trans. Power Electr., S., pp. 625-633, Nov. 1995.

[14] Arbetter, B. \& Maksimovic, D., Feedforward Pulse Width Modulators for Switching Power Converters, IEEE Trans. Power Electr., 12(2), pp. 361-368, March 1997.

[15] Garcera, G., Figueres, E. \& Mocholi, A., Novel Three-Controller Average Current Mode Control of DC-DC PWM Converters with Improved Robustness and Dynamic Response, IEEE Trans. Power Electr., 15, pp. 516-528, May 2000.

[16] Choi, B., Kim, J., Cho, B.H., Choi, S. \& Wildrick, C.M., Designing Control Loop for DC-DC Converters Loaded with Unknown AC Dynamics, IEEE Trans. Ind. Electr., 49, pp. 925-932, August 2002.

[17] Yazdani, A. \& Iravani, R., Control of High-Performance Switched Mode Rectifier System, IEE Proc. Electr. Power Appl., 152(6), pp. 1451-1458, Nov. 2005.

[18] Wan, K., Liao, J. \& Ferdowski, M., Control Methods in DC-DC Conversion - A Comparative Study, Proc. IEEE Aplied Power Electr. Conf., pp. 921-926, 2007. 